\title{
ESTRATEGIAS DE COMERCIO E INTEGRACIÓN DE MÉXICO
}

\author{
Carlos Gómez Chiñas* \\ Grupo de Investigación Proyección Empresarial
}

\section{INTRODUCCION}

El objetivo del presente trabajo es realizar un análisis detallado de las estrategias de comercio e integración seguidas por las sucesivas administraciones del gobierno mexicano a partir de 1983. Se trata de determinar no sólo si se alcanzaron los principales objetivos de la estrategia de apertura iniciada a mediados de la década de los ochenta sino, además, si esta consecución fue la más eficiente posible.

El trabajo se encuentra estructurado de la siguiente manera, en la primera sección se revisan los rasgos esenciales de la política comercial puesta en marcha a partir de mediados de la década de los ochenta. En la segunda, se analiza uno de esos rasgos, la política de negociaciones comerciales internacionales, poniendo énfasis en lo que, sin duda constituye el elemento fundamental de la política comercial de las últimas décadas, el TLCAN. La tercera sección está dedicada a los resultados de la estrategia seguida y finalmente, se esbozan unas conclusiones preliminares.

Uno de los elementos claves de esta estrategia ha sido, sin duda, la negociación de acuerdos de libre comercio con diversos países. Esta estrategia forma parte de un conjunto más amplio de medidas, que constituyen la política comercial.

Uno de los principales objetivos iniciales de la política comercial era el cambio estructural en la industria y en el comercio exterior. Sin lugar a dudas que se han obtenido algunos logros. Así, uno de los rasgos sobresalientes del desempeño de la economía mexicana desde finales de la década de los ochenta ha sido su creciente participación en el comercio internacional que la ha llevado de ser una de las economías más cerradas a una de las más abiertas y la han convertido en la primera exportadora de América Latina, a finales de la década de los noventa, de tal forma que las exportaciones mexicanas "representan más del $40 \%$ del total de las ventas externas latinoamericanas y caribeñas; además, a lo largo de la década de los 90, su desempeño fue más dinámico que el promedio del resto de la región. Por ejemplo, entre 1992 y 1998 las exportaciones mexicanas crecieron a una tasa promedio de 13\%, mientras que las exportaciones latinoamericanas, sin incluir a México, tuvieron un aumento de poco más de 7\%".' En el año 2001, México ocupó el lugar número 12 entre las principales economías exportadoras, el séptimo si se excluye el comercio intracomunitario de la Unión Europea, y fue la undécima economía en lo que al valor de las importaciones se refiere, nuevamente séptima si se excluye el comercio intracomunitario.

En los años recientes, el crecimiento de las exportaciones ha contribuido con la mitad del crecimiento del Producto Interno Bruto (PIB). Es cierto que desde 1994, el número de exportadores se ha incrementado en casi 70 por ciento y que actualmente más de 35 mil empresas mexicanas están vendiendo sus productos en el exterior pero el mayor peso de las exportaciones recae en sólo unas cuantas docenas de grandes empresas. ${ }^{2}$ Más específicamente, un pequeño grupo de empresas exportadoras nacionales y extranjeras, entre 264 y 312 empresas durante 19931998, concentró en promedio el $51.86 \%$ de las exportaciones mexicanas ${ }^{3}$

* Profesor Titular del Departamento de Economía, UAM-Azcapotzalco.

CEPAL, "El desafío de las nuevas negociaciones comerciales multilaterales para América Latina y el Caribe", Serie Temas de Coyuntura, número 7 , CEPAL, Santiago de Chile, 1999.

2 Cfr. Presidencia de la república, Libre Comercio. Factor clave en el crecimiento económico, México, 2000.

3 Enrique Dussel Peters, El Tratado de Libre Comercio de Norteamérica y el Desempeño de la Economía de México, Documentos de la CEPAL, México, 2000. Pág.47. 
Estas exportaciones han contribuido a la creación de empleos, pero, żlo han hecho en el grado pertinente y han coadyuvado al desarrollo y fortalecimiento del mercado interno? . De acuerdo con Dussel, no, ya que una de las características más reveladoras de las principales empresas exportadoras, extranjeras y nacionales es su discreta participación en el empleo. En promedio, han participado con $3.41 \%$ del empleo nacional durante 1993-1998. Las actividades y empresas que concentran $93.35 \%$ de las exportaciones- alrededor de 3400 empresas incluyendo maquiladoras-en promedio sólo participan con $5.65 \%$ del empleo nacional.

La tasa de crecimiento de la economía mexicana fue modesta en el periodo, 1985-1993, posterior a la reforma, y previo a la crisis de 1995. Así, la tasa de crecimiento promedio anual del PIB, medido a precios de 1980, en el periodo 1985-1994 fue de 1.9 por ciento.

Como resultado de la devaluación de la moneda iniciada en diciembre de 1994, durante 1995-1997 hubo superávit en la balanza comercial y en 1998 hubo déficit, mismo que experimentó una disminución en 1999. En el año 2000, este déficit experimentó un incremento de 43 por ciento. En 2001 aunque siguió aumentando, sólo lo hizo en 22 por ciento, lo que representó un déficit de 9,733 millones de dólares. En 2002, el déficit comercial disminuyó a 7,997 millones de dólares con lo que se revierte la tendencia al aumento que se venía observando desde 1999.

\section{RASGOS ESENCIALES DE LA POLITICA COMERCIAL}

Después de dos intentos fallidos de liberalización comercial, México puso en práctica, a partir de 1985, una estrategia de liberalización de las importaciones y de gradual desmantelamiento de los controles comerciales que habían aislado prácticamente a los productores domésticos de la competencia externa. Cabe mencionar que el proceso de liberalización fue precedido y seguido por fuertes aumentos en el tipo de cambio real que dieron al sector industrial cierto margen de maniobra para realizar el ajuste.

Antes del comienzo de la liberalización comercial, México hacía uso de una gran variedad de instrumentos para controlar las importaciones, estimular la producción industrial y orientar al sector manufacturero hacia los mercados externos. Existía una estructura arancelaria con alta dispersión y una tasa máxima del $100 \%$ donde la mayor parte de las fracciones arancelarias estaban sujetas al permiso previo de importación. Adicionalmente a estos instrumentos, también se utilizaba profusamente el precio oficial, el cual se dejó de utilizar en 1988, como parte de los compromisos contraídos al adherirse al GATT, casi una quinta parte de las importaciones estaba afectada por el precio oficial. Para contrarrestar el sesgo antiexportador generado por tales medidas, los exportadores de productos no tradicionales disfrutaban de estímulos fiscales. ${ }^{4}$

La liberalización comercial comenzó con la eliminación de los controles cuantitativos de un gran número de fracciones arancelarias y con un alza en los aranceles para compensar parcialmente la desprotección que significó la eliminación de tales permisos previos. En 1987 se profundizó la reforma comercial, se simplificó el arancel que fue reducido a cinco tasas con un rango de cero a $20 \%$ y una media arancelaria de $10.4 \%$ y se hizo extensiva a las exportaciones, eliminándose el requisito de permisos para muchas de ellas.

Fueron suprimidos los instrumentos tradicionales de subsidio a las exportaciones, en parte como consecuencia de la adhesión de México al GATT y en parte como consecuencia de las negociaciones bilaterales con los Estados Unidos. Igualmente, se

4 4. Véase CEPAL, América Latina y el Caribe. Políticas para Mejorar la Inserción en la Economía Mundial, CEPAL- FCE, Santiago de Chile, 1998. Pág. 161. 
redujo significativamente el uso de políticas de promoción industrial. "En particular, asociado a la liberalización comercial y al TLCAN, se desactivó el uso de incentivos comerciales, ya fueran arancelarios o administrativos" 5 .

El ingreso de México al Acuerdo General sobre aranceles aduaneros y comercio (GATT) en 1986, constituyó, sin duda, la primera señal sobre la irreversibilidad del proceso de apertura unilateral iniciado en 1985 y la consolidación del proceso de cambio estructural iniciado en 1983.

Como parte de su adhesión al GATT en 1986, México consolidó sus tasas arancelarias en un máximo ad valorem del 50 por ciento. En la Ronda Uruguay, México acordó en reducir las tasas consolidadas del 50 al 35 por ciento para los productos no agropecuarios, con ciertas excepciones, las cuales afectan a un conjunto relativamente amplio de productos manufacturados, cuyas tasas consolidadas se mantienen por lo general en el 50 por ciento.

Entre 1993 y 1997, México eliminó de manera unilateral aranceles de nación más favorecida a más de 1200 productos; los productos libres de arancel pasaron de 414 en 1993 a 1658 en 1997. Los principales bienes sobre los cuales México adoptó esta eliminación arancelaria fueron insumos y maquinaria utilizados en los sectores agrícola, químico, eléctrico, electrónico, textil y editorial. A pesar de que el arancel promedio simple se mantuvo en alrededor del 13 por ciento después de 1993, el arancel promedio ponderado se redujo de manera significativa pasando del 7.8 por ciento en 1993 al 2.9 en 1996 y al 2.7 por ciento en 1997.6

El cambio más importante en el uso de los aranceles ha sido la aplicación de nuevas preferencias regionales, que han reducido el promedio de los aranceles ponderados en función del comercio pero, al mismo tiempo, han ampliado la diferencia entre el promedio simple de las tasas de Nación más Favorecida (NMF), 16.5 por ciento en 2001 y las tasas preferenciales, por ejemplo, las importaciones procedentes de los Estados Unidos están sometidas a un arancel promedio del 4.2 por ciento. Asimismo, es pertinente mencionar que la base de valoración en aduana depende del origen de las importaciones: FOB para las procedentes de los socios del TLCAN y CIF para otras importaciones, lo que suscita la posibilidad de una distorsión neta del comercio.

En el caso de ciertos productos sensibles como la carne de bovino, el vestido y el calzado, se han aumentado las tasas NMF haciendo uso del margen de flexibilidad que conceden las consolidaciones de tasas máximas. ${ }^{7}$ En términos generales se tiene que la protección arancelaria concedida a los productos agropecuarios es sustancialmente más elevada que la de los productos no agropecuarios, la tasa correspondiente a los primeros fue, en 2001 , de 24.9 por ciento mientras que la correspondiente a los no agropecuarios fue de 15.6 por ciento.

México, utiliza permisos de importación para proteger ramas de producción nacionales, particularmente en la industria del automóvil. Como la mayoría de los países miembros de loa $\mathrm{OECD}$, México también recurre a las medidas antidumping. De hecho, la Unidad de Prácticas Comerciales Internacionales de la Secretaría de Economía, la instancia encargada de realizar las investigaciones antidumping, aplica uno de los sistemas de defensa comercial más activos del mundo. Entre 1987 y 2001 se llevaron a cabo 237 investigaciones (219 por dumping y 18 por subvenciones), de las cuales 178 dieron lugar a la imposición de derechos provisionales y 119 a derechos definitivos. En el

\footnotetext{
5 5. CEPAL, op. cit. pág. 162.

- OMC, "Exámenes de las políticas comerciales: Primer comunicado de prensa, resumen del informe de la secretaría y del informe del gobierno". Pág. 13. http://www.wto.org/spanish/tratop_s/tp063 s.htm. 1997

7 OMC(1997), Op. Cit. Pág.2.
} 
Estrategias de comercio e integración de México

Carlos Gómez Chiñas

periodo 1987-2001, los países más afectados por las investigaciones antidumping de México fueron, los Estados Unidos, China y Brasil. Así, la proporción de investigaciones que dieron lugar a la imposición de derechos es considerablemente mayor en el caso de China que en cualquier otro país, por lo que China ocupa el primer lugar en cuanto al número de derechos impuestos. $^{8}$

"La política comercial de México sigue estando estrechamente asociada con la promoción de las inversiones extranjeras, cuyas normas han formado parte a la vez de sus iniciativas multilateral y preferencial". 9 Esto no puede ser de otra manera si se considera que las exportaciones de la industria automotriz $^{10}$ representaron en 1993, 22.4 por ciento de las exportaciones del sector no maquilador y en 2002 ya representaban 30.8 por ciento de tales exportaciones. Si, además, se considera al sector maquilador, donde la participación de la Inversión Extranjera Directa (IED) es abrumadora, la importancia de la inversión extranjera en la estrategia de comercio exterior de México queda más clara. Así, en 1993, las exportaciones de maquiladoras representaron el 42.1 por ciento de las exportaciones totales en tanto que sus importaciones sólo participaron con el 25.2 por ciento de las importaciones totales, mientras que en 2002, la participación de las exportaciones de las maquiladoras en las totales ya fue de 48.6 por ciento en tanto que sus importaciones representaron ya el 35.2 por ciento de las totales.

Adicionalmente al uso de los aranceles, se siguen utilizando permisos de importación para productos sensibles por razones de seguridad nacional, salud pública y protección de la industrias nacionales. En 2001, las importaciones procedentes de fuentes NMF sujetas a permisos previos incluían los productos petroquímicos, los vehículos y los neumáticos, máquinas, vestidos y máquinas de oficina usados. En el caso de los vehículos y las máquinas, sólo se conceden permisos cuando ningún producto de producción nacional puede sustituir al producto extranjero. Desde 1998, México ha utilizado un sistema de concesión de licencias de importación para reunir estadísticas sobre el precio de ciertos bienes procedentes de determinados países antes de que se lleve a cabo su importación.

\section{LAS NEGOCIACIONES COMERCIALES INTERNACIONALES}

Los tratados de libre comercio han sido un elemento fundamental de la política comercial de México en la últimos diez años. Estos tratados comenzaron a negociarse antes de la conclusión de las negociaciones de la Ronda Uruguay con el objetivo de aumentar la competitividad de la economía mexicana y de abrir nuevos mercados de exportación. ${ }^{11}$

Además del TLCAN, México tiene en vigor 9 acuerdos de libre comercio: con Chile (1999), con Bolivia (1995), con Colombia y Venezuela en el marco del Grupo de los tres (1995), con Costa Rica (1995), con Nicaragua (1998), con la UE (2000), con Israel (2000), con la Asociación Europea de Libre Comercio(2001), con el Triángulo del Norte (Guatemala, Honduras y el Salvador 2001) y un Acuerdo de Complementación Económica con Uruguay (2001). Dentro de estos, sin lugar a dudas que el más relevante, es el TLCAN, ya que "con la entrada en vigor del TLCAN, las condiciones generales de la economía se modificaron de manera importante. Por un lado, con el tratado se registraba un avance trascendental en la política de cambio estructural del gobierno. El tratado significaba no sólo profundizar en la apertura a los flujos

8 OMC(2002), “Examenes de las políticas comerciales. México 2002. Informe de la secretaría, Ginebra, pág. 62.

9 OMC(2002), Op. Cit. pág. xi.

${ }^{10}$ En las exportaciones de la industria automotriz se incluyen partes sueltas y motores.

$11 \mathrm{OMC}(1997)$, Op. Cit, pág. 18. 
comerciales y de inversión sino que también proporcionaba un viso de permanencia a la misma, difícil de obtener por otros medios"12. Una gran variedad de intereses específicos afectados adversamente por las políticas de apertura comercial, privatización y desregulación, hubieran encontrado en el rechazo del TLCAN un gran escaparate para presionar a fin de que se revirtieran esas políticas.

La mayor parte del comercio de bienes entre los miembros del TLCAN fue liberalizada entre 1994 y 1998. Al mes de mayo de 2001, la tasa arancelaria media para las importaciones procedentes de los Estados Unidos era del 1.1 por ciento y para las importaciones procedentes del Canadá del 1.6 por ciento. Este proceso quedó completado para la mayoría de los productos restantes el primero de enero de 2003 y el primero de enero de 2004 en lo que respecta a los automóviles nuevos. La plena liberalización de un número reducido de productos, entre los que cabe mencionar los frijoles, el maíz y la leche, está prevista para el año 2008. El TLCAN prevé la liberalización paulatina de las importaciones de vehículos usados, aunque estas comenzarán a liberalizarse a partir de 2009, este proceso concluirá el primero de enero de 2019.13

"La estrategia comercial de México se ha alejado progresivamente de las reformas unilaterales, consolidadas dentro del sistema multilateral, para optar por una liberalización negociada a escala regional. La reducción de los obstáculos no arancelarios al comercio y la liberalización de las inversiones producto de acuerdos preferenciales con otros países han beneficiado muchas veces a terceros, por ejemplo en la esfera de los servicios. Al modelar sus nuevos acuerdos de libre comercio según el modelo del
TLCAN, México ha procurado que estos acuerdos tengan un alto grado de uniformidad aunque la diferencia de regímenes en materia de excepciones, plazos de aplicación y normas de origen den lugar a diversas complejidades" ${ }^{\prime 14}$. Sin embargo, las ventajas que se derivan de tales acuerdos son de carácter temporal, por lo que no deberían sustituir los esfuerzos por mejorar la competitividad global de la economía interna. Además, el número cada vez mayor de acuerdos comerciales concertados por el país suscita preocupación en cuanto a su costo administrativo, en la medida en que las diferencias entre los acuerdos, por ejemplo en lo tocante a las normas de origen, hacen que los agentes económicos dedicados a las actividades de comercio exterior tengan que dominar diferentes normas y procedimientos. ${ }^{15}$

\section{LOS SALDOS DE LA ESTRATEGIA SEGUIDA}

El éxito de la política comercial seguida por México en los últimos años se refleja claramente en los indicadores macroeconómicos. A esta política comercial se atribuye que la crisis de 1995 no haya sido más profunda, que no se hayan perdido más empleos y que el país haya logrado recuperar, en relativamente poco tiempo, el crecimiento económico. ${ }^{16}$

A partir de la crisis cambiaria las actividades exportadoras en México se volvieron altamente rentables. Sin duda, la fuerte y rápida expansión de las empresas exportadoras estuvo relacionada con las medidas de apertura instrumentadas a partir de mediados de los ochenta y la profundización de las mismas vinculadas al tratado. Como resultado de esta profundización, la economía mexicana adoptó una estructura productiva más especializada, en la que ciertos rubros de producción fueron sustituidos por

\footnotetext{
12 Ignacio Trigueros, "El Tratado de Libre Comercio de América del Norte y la Situación Macroeconómica de México", en Beatriz Leycegui y Rafael Fernández de Castro (comps.), ¿̇Socios Naturales? Cinco Años del Tratado de Libre Comercio de América del Norte, Miguel Angel Porrúa, México, 2000, pág. 106.

${ }^{13}$ Cfr. OMC(2002), Examen de las Políticas Comerciales. México. Informe de la Secretaría. Ginebra, 2002. p. 26.

$14 \mathrm{OMC}(1997)$, op . cit. pág. 6.

$15 \mathrm{OMC}(2002)$, op. cit. 26

16 Ivonne Stinson Ortiz, "La política comercial mexicana", Perspectivas Americanas, Publicación electrónica del Instituto de las Américas, junio 2000 www.iamericas.org. P. 3.
} 
Estrategias de comercio e integración de México

Carlos Gómez Chiñas

importaciones mientras que una mayor proporción de recursos domésticos se orientó a la producción de bienes de exportación ${ }^{17}$.

Veamos a continuación cuáles han sido algunos de los resultados de la estrategia seguida sobre la estructura del comercio internacional de México. En 1985, año en que se inició el proceso de apertura comercial, cuando no se incluían a las maquiladoras dentro de la balanza comercial, las exportaciones alcanzaron un monto de 21,663.8 millones de dólares, mientras que en 2002 ya fueron de 82,641.2 millones de dólares, sin incluir a las maquiladoras, mientras que si se incluyen, el monto sube a 160,682 millones de dólares. Como resultado de la recesión por la que atravesó la economía estadounidense, en 2001 las exportaciones disminuyeron, aunque en 2002 se recuperaron ligeramente, su monto fue inferior a logrado en 2000, año en que representaron 166,454.8 millones de dólares. Aún sin considerar a las maquiladoras, el crecimiento es impresionante. Así, de 1985 a 2002, las exportaciones totales crecieron $500.5 \%$, lo que significó una tasa de crecimiento medio anual(tcma) de 11.1, las exportaciones de manufacturas sin considerar a las maquiladoras lo hicieron en $894.8 \%$, o sea que tuvieron una tcma de $14.5 \%$, mientras que las importaciones aumentaron entre 1985 y 2002 en $818.8 \%$, lo que representó una tcma de 13.9\%. Por su parte, el PIB, medido en dólares, creció entre 1985 y 2002 en 317.2 por ciento, lo que significó una tcma de 8.8 por ciento, por debajo del crecimiento del comercio exterior (Cuadro 1).

Del cuadro 1, se puede inferir que las exportaciones no maquiladoras crecieron en el periodo 1995-2002 en $70.6 \%$, mientras que las exportaciones de maquiladoras lo hicieron en $150.9 \%$. De lo anterior, se puede afirmar que el componente más dinámico de las exportaciones mexicanas son las realizadas por las maquiladoras, las cuales hacen uso intensivo de mano de obra poco calificada y tienen una marcada orientación hacia el mercado de los Estados Unidos. La economía mexicana hoy es mucho más abierta que en 1983. En ese año las exportaciones e importaciones de mercancías representaron el $31.78 \%$ del PIB, mientras que en 2000 esa proporción fue del 59.34\%. Veamos con mayor detalle esta relación. En la última parte de la década de los ochenta la proporción entre exportaciones e importaciones con relación al producto interno bruto alcanzó un máximo del 34\%. En 1993, cae hasta el $29 \%$, esto a pesar de que para este año ya se consideraba a la industria maquiladora dentro de la balanza comercial. En 1995, el grado de apertura comercial fue del $53.11 \%$. La causa fundamental de este impresionante aumento, pasó de $33.33 \%$ a $53.11 \%$ en sólo un año, es la caída del PIB medido en dólares que fue de $32 \%$, aunque las exportaciones también crecieron de manera considerable, $30.5 \%$, mientras que las importaciones caían en $8.7 \%$, como resultado de la devaluación. Esta proporción se ha mantenido por encima del $50 \%$ a pesar de la recuperación del PIB. Así, en 1999 fue de 58.1\%, mientras que en 2002 disminuyó a 51.7\%.

No se puede afirmar tajantemente, para el período 1995-2001, que "la devaluación del peso, sin lugar a dudas, ha sido una de las principales causas de esta dinámica" ${ }^{\prime 18}$, ya que el TLCAN también ha tenido una influencia notable en este desempeño. Así, en la gráfica 1 se puede apreciar que durante el período 1998. 2001 no hay una relación clara entre las variaciones del índice del tipo de cambio real y el crecimiento de las exportaciones, por ejemplo, se observa, entre 19982000, que las exportaciones siguen creciendo mientras que el índice del tipo de cambio real basado en el costo unitario de la mano de obra en la industria manufacturera no maquiladora disminuye. ${ }^{19}$ Entre

\footnotetext{
17 Véase Ignacio Trigueros, op. cit. págs. 120-121

${ }_{18}$ Enrique Dussel Peters, El Tratado de Libre Comercio de Norteamérica y el Desempeño de la Economía en México, Documentos de la CEPAL, México, 2000. Pág. 18.

${ }^{19}$ Un aumento en el índice significa una depreciación del peso y una disminución representa una apreciación.
} 
2000 y 2001 ocurre lo contrario ya que mientras el peso se deprecia, las exportaciones disminuyen.

Otra relación donde se puede apreciar claramente la transformación ocurrida en el comercio exterior de México es en la participación de las exportaciones de manufacturas en las exportaciones totales. Como se puede observar en el cuadro 2, en 1983 las exportaciones de manufacturas representaban el $21 \%$ de las exportaciones totales, en 1988, esta participación casi se había duplicado al representar 40\%, después de caer ligeramente en 1990, en 1993 ya las exportaciones de manufacturas representaron el 82.1 por ciento de las exportaciones totales, un aumento del cien por ciento en su participación en las exportaciones totales en sólo cinco años. Sin embargo, este último dato hay que tomarlo con muchísima reserva ya que a partir de 1991 se incluyen las exportaciones de las maquiladoras en la balanza comercial y no en la de servicios como se hacía tradicionalmente. Después de un virtual estancamiento en 1993-94, inició un repunte que alcanzó su máximo en 1998 cuando representaron el $90.3 \%$ de las exportaciones totales. En 2002, esta participación fue del $88.4 \%$. Sin lugar a dudas que ha sido notable el desempeño de las exportaciones de manufacturas.

En contrapartida las exportaciones petroleras han venido perdiendo importancia dentro de las exportaciones totales. Así, mientras que en 1983 representaron el $72 \%$ de las exportaciones totales, en 1993, ya sólo representaban el 14.3\%, esta participación ha continuado a la baja de tal forma que en 2002, las exportaciones petroleras sólo representaron el 9 por ciento de las exportaciones totales ${ }^{20}$, lo cual indica un cambio notable en la estructura de las exportaciones mexicanas y una mayor diversificación de las mismas.

En el sector agropecuario muchas actividades se han modernizado y beneficiado de un acceso creciente a los mercados externos, especialmente el mercado estadounidense, pero otras siguen desenvolviéndose en una escala reducida y esencialmente orientada al consumo de subsistencia. En general la productividad de la mano de obra del sector es muy inferior a la media nacional.

En lo que se refiere al comportamiento de la balanza comercial, en el cuadro 1 se observa que después de experimentar déficit crecientes, se volvió positiva entre 1995 y 1997. En 1998, el déficit fue de 7913 y disminuyó en 1999 a 5583.7 millones de dólares pero volvió a aumentar en el año 2000 cuando alcanzó la cifra de 8003 millones de dólares. En 2001, el déficit aumentó nuevamente para alcanzar los 9733 millones de dólares, aunque en 2002 disminuyó ligeramente a 7997 millones de dólares. Si hacemos a un lado a las maquiladoras el déficit es sustancialmente mayor y sostenidamente creciente entre 1997 y 2000, aunque durante 2001 y 2002 disminuyó, todavía es más de tres veces el déficit comercial total, lo cual podría ser un síntoma de problemas respecto de la competitividad de la industria no maquiladora mexicana y una evidencia de la ausencia de una política industrial adecuada. Hay que hacer notar que el problema no es tanto por una falta de crecimiento de las exportaciones sino por el mayor dinamismo de las importaciones. Así, en el periodo 1995-2002 las exportaciones totales no maquiladoras crecieron a una tasa media anual de 7.9 por ciento mientras que las importaciones correspondientes lo hicieron a una tasa de 17.8 por ciento, más del doble.

Se puede afirmar que la industria no maquiladora es la determinante de este déficit, aunque el sector agropecuario también contribuye a esta tendencia comercial negativa. EI TLC con Estados Unidos y Canadá no ha favorecido un mejoramiento de esta tendencia en este sector ${ }^{21}$.

\footnotetext{
${ }^{20}$ Estos cálculos se realizaron con base en datos del Banco de México, Informe Anual, 1984 y 2002.

${ }^{21}$ Véase Carlos A. Rozo Bernal, "El modelo exportador mexicano. ¿̇Éxito o fracaso? En Diana R. Villarreal González (comp.), La Política Económica y Social de México en la Globalización, UAM- Miguel Ángel Porrúa, México, 2000. p. 86.
} 
Estrategias de comercio e integración de México

Carlos Gómez Chiñas

Veamos ahora el saldo regional de la balanza comercial. Hasta 1994, México había tenido un saldo negativo en su comercio con Los Estados Unidos. Desde 1995 este saldo ha sido persistentemente positivo lo que ha compensado parcialmente los crecientes saldos negativos con el resto del mundo. En el cuadro 3 se puede observar que el comercio con Canadá ha tenido saldos negativos en el período 1998-2002. Se puede decir que el comercio con Canadá ha sido muy dinámico, sólo que este dinamismo no ha sido parejo ya que mientras las exportaciones mexicanas a Canadá crecieron a una tasa media anual de 8.2 por ciento en el periodo de vigencia del tratado, 1994-2002, las exportaciones totales lo hicieron a una tasa de 12.9 por ciento, en tanto que las importaciones procedentes de Canadá crecieron a una tasa media anual del 13.6 por ciento, en el periodo referido, que está por encima del 9.9 por ciento anual al que crecieron las importaciones totales en ese período.

Como resultado de lo anterior, las importaciones procedentes de Canadá han ganado importancia dentro de las totales. Así, las importaciones procedentes de Canadá representaban el 1.8 por ciento de las totales en 1993, un año antes de la puesta en marcha del TLCAN, mientras que esta participación alcanzó el 2.7 por ciento en el 2002. Por su parte, en 1993, las exportaciones a Canadá representaban el 3 por ciento de las exportaciones mexicanas, en tanto que en 2002 dicha participación disminuyó a 1.8 por ciento. En lo que se refiere al comercio MéxicoCanadá, se puede decir que el TLCAN ha servido más para impulsar las exportaciones canadienses a México que las mexicanas a Canadá.

El saldo de la balanza comercial con la zona del TLC ha sido persistentemente positivo desde 1995. El comercio con el resto de América también ha tenido saldos persistentemente positivos desde 1993. Esto podría explicar el afán del gobierno de suscribir
Acuerdos de Libre Comercio al por mayor, aunque si uno se detiene en el caso de Canadá, este afán ya no tendría tanto sustento.

De acuerdo con Dussel ${ }^{22}$, se puede afirmar que las actividades exportadoras manufactureras, motor del crecimiento de la economía mexicana, se encuentran altamente concentradas en un relativamente pequeño grupo de empresas maquiladoras y de otra índole, con limitaciones para generar o profundizar sus encadenamientos con otras empresas establecidas en México, así como con una reducida participación en el empleo total.

Sin embargo, desde la perspectiva oficial, el panorama es sustancialmente diferente, así las exportaciones son el sector más dinámico de la economía mexicana y el primer generador de empleos. Los empleos en el sector exportador tienden a ser mejor remunerados. En 1999, las empresas que exportaron el $80 \%$ o más de sus ventas pagaron salarios $64 \%$ más altos que los del resto de la industria. En aquellas empresas que exportaron más de $60 \%$ de su producción, los salarios fueron $39 \%$ superiores a los del resto de la industria. Igualmente, el número de exportadores se ha incrementado. Actualmente, más empresas mexicanas, en su mayoría de menor tamaño, están vendiendo sus productos en el exterior, contribuyendo con ello a la creación de empleos, así como al desarrollo y fortalecimiento del mercado interno. ${ }^{23}$

No obstante esto último, se puede afirmar que se ha desaprovechado un gran potencial de desarrollo tecnológico, de generación de empleos y de procesos de aprendizaje en general, ya que la mayor parte de las empresas mexicanas no han participado en este proceso de integración y crecimiento mediante las exportaciones.

De acuerdo con Carlos Rozo, se puede concluir que "la estrategia exportadora ha sido incapaz de

${ }^{22}$ Op. Cit. Pág. V.

${ }_{23}$ Secretaría de Economía, México: Negociaciones Comerciales Internacionales, México, D.F. Abril de 2001. pág. 4. 
convertirse en una fuerza de arrastre para el crecimiento del mercado nacional, especialmente por la incapacidad que ha tenido para impulsar la oferta por medio de la producción nacional de bienes intermedios y de capital y la demanda por su incapacidad para mejorar el valor adquisitivo del salario. ${ }^{24}$

\section{CONCLUSIONES}

Uno de los resultados más relevantes de la estrategia comercial seguida es el dinamismo de las exportaciones, las cuales se han convertido en el motor de la economía. Otro resultado notable es la creciente participación del comercio de manufacturas en el comercio total de bienes.

Destaca la importancia de los Estados Unidos como destino y origen de las exportaciones e importaciones mexicanas, durante 2000 Estados Unidos absorbió el $88.7 \%$ de las exportaciones mexicanas y proporcionó el $73 \%$ de sus importaciones. En 2002, esas proporciones fueron de $88.96 \%$ por ciento y 63.2 por ciento, respectivamente. A partir de estos datos se puede afirmar que México está diversificando el origen de sus importaciones pero no el destino de sus exportaciones.

La liberalización o racionalización de las importaciones es sólo uno de los ingredientes de una reforma comercial integral y como lo demuestra la experiencia mexicana, no es una condición suficiente para que el comercio exterior se constituya como un motor que lleve a la economía a un crecimiento sostenido y menos al desarrollo, se necesita de una política activa para alcanzar tal objetivo.

Con todo sus logros, es evidente que la política comercial no se ha traducido en una mejora de la distribución del ingreso, ni en la disminución de los niveles de pobreza. Además, el empleo no ha aumentado en los niveles requeridos por la población.

${ }^{24}$ Op. Cit, p. 96

\section{BIBLIOGRAFÍA}

BANCO DE MÉXICO, Informe Anual, varios años.

CEPAL, América Latina y el Caribe. Políticas para Mejorar la inserción en la Economía Mundial, CEPALFCE, Santiago de Chile, 1998.

CEPAL, "El desafío de las nuevas negociaciones comerciales multilaterales para América Latina y el Caribe", Serie Temas de Coyuntura, número 7, CEPAL, Santiago de Chile, 1999.

Dussels Peters, El Tratado de Libre Comercio de Norteamérica y el Desempeño de la Economía de México, Documentos de la CEPAL, México, 2000.

OMC, "Exámenes de las políticas comerciales: Primer comunicado de prensa, resumen del informe de la secretaría y del informe del gobierno". http//www.wto. org/spanish/tratop_s/tpr_s/tp063_s.htm.1997.

OMC, "México, Informe de la Secretaría", Examen de las Políticas Comerciales, Ginebra, 2002.

Presidencia de la República, Libre Comercio. Factor Clave en el Crecimiento Económico, México, 2000.

Secretaría de Economía, México: Negociaciones Comerciales Internacionales, México, 2001.

Rozo Bernal, Carlos A. "El modelo exportador mexicano. ¿Éxito o fracaso? En Diana R. Villarreal González (comp..), La Política Económica y Social de México en la Globalización, UAM- Miguel Ángel Porrúa, México, 2000.

Stinson Ortiz, Ivonne, "La política comercial mexicana", Perspectivas Americanas, Publicación electrónica del Instituto de las Américas, junio 2000, www.iamericas.org

Trigueros, Ignacio, "El Tratado de Libre Comercio de América del Norte y la situación Macroeconómica de México" en Beatriz Leycegui y Rafael Fernández de Castro (comps.), ¿̇Socios Naturales? Cinco Años del Tratado de Libre Comercio de América del Norte, Miguel Angel Porrúa, México, 2000.

Revista Respuestas - Universidad Francisco de Paula Santander Año 9 No. 1 
Estrategias de comercio e integración de México

Carlos Gómez Chiñas

Cuadro 1. México: Comercio Exterior y PIB (Millones de dólares)

\begin{tabular}{|c|c|c|c|c|c|c|c|c|c|}
\hline Año & $\begin{array}{c}\text { Exportaciones } \\
\text { totales }\end{array}$ & $\begin{array}{l}\text { Importa- } \\
\text { ciones } \\
\text { totales }\end{array}$ & $\begin{array}{c}\text { Exportaciones } \\
+ \\
\text { Importaciones } \\
\end{array}$ & $\begin{array}{c}\text { Exportaciones } \\
\text { totales sin } \\
\text { maquiladora } \\
\end{array}$ & $\begin{array}{c}\text { Importaciones } \\
\text { totales sin } \\
\text { maquiladora }\end{array}$ & $\begin{array}{c}\text { Exportaciones } \\
\text { de } \\
\text { manufactura }\end{array}$ & \begin{tabular}{|c|} 
Export. de \\
manufac. \\
sinmaquilado
\end{tabular} & \begin{tabular}{|c|} 
PIB \\
Manufacturero \\
a precio
\end{tabular} & PIB \\
\hline 1983 & 25953 & 11849 & 37802 & 22312 & 8550.9 & 5448 & 5448 & 163139 & 118960 \\
\hline 1984 & 29100 & 15916 & 45016 & 24196 & 11254.3 & 6985 & 6985 & 171425 & 159146 \\
\hline 1985 & 26757 & 18359 & 45116 & 21663.8 & 13212.2 & 6428 & 6428 & 181823 & 152740 \\
\hline 1986 & 21804 & 16784 & 38588 & 16031 & 11432.4 & 7909 & 7909 & 172135 & 124148 \\
\hline 1987 & 27600 & 18812 & 46412 & 20656.2 & 11222.9 & 10427 & 10427 & 177498 & 137509 \\
\hline 1988 & 30692 & 28082 & 58774 & 20561.1 & 18898.2 & 12268 & 12268 & 178416 & 181826 \\
\hline 1989 & 35171 & 34766 & 69937 & 22764.9 & 23409.7 & 13091 & 13091 & 192500 & 204437 \\
\hline 1990 & 40711 & 41593 & 82340 & 26773.1 & 29798.5 & 14861 & 14861 & 205524 & 297538 \\
\hline 1991 & 42688 & 49967 & 92655 & 26854.5 & 38184.1 & 32307 & 15679 & 212578 & 286859 \\
\hline 1992 & 46196 & 62129 & 108325 & 27515.6 & 48192.6 & 36168 & 16740 & 221427 & 363662 \\
\hline 1993 & 51886 & 65367 & 117253 & 30033 & 48923 & 42617 & 19832.1 & 219934 & 403243 \\
\hline 1994 & 60882 & 79346 & 140228 & 34613 & 58879.7 & 50402 & 24132.8 & 228892 & 420773 \\
\hline 1995 & 79542 & 72453 & 151995 & 48438.3 & 48274.3 & 66558 & 35454.6 & 217582 & 286184 \\
\hline 1996 & 96000 & 89469 & 185469 & 59079.4 & 58964.1 & 80305 & 43384.3 & 241152 & 332337 \\
\hline 1997 & 110431 & 109808 & 220239 & 65265.8 & 73475.7 & 94802 & 49636.6 & 265113 & 400870 \\
\hline 1998 & 117460 & 125373 & 242833 & 64376.4 & 82816.3 & 106062 & 52979.2 & 284643 & 421026 \\
\hline 1999 & 136391.1 & 141975 & 278365.9 & 72537.5 & 91565.5 & 122084.5 & 58231 & 296631 & 479446 \\
\hline 2000 & 166454.8 & 174458 & 340912.6 & 86987.4 & 112749 & 145334.2 & 65866.8 & 317092 & 574514 \\
\hline 2001 & 158542.3 & 168275 & 326817.6 & 81562 & 110797.9 & 141345.6 & 64472 & 305318 & 617822 \\
\hline 2002 & 160682 & 168679 & 329361 & 82641.2 & 109382.9 & 141988.8 & 63947.9 & 303407 & 637269 \\
\hline
\end{tabular}

A partir de 1991 se incluye la industria maquiladora en las exportaciones de manufacturas. El PIB manufacturero a precios de 1993 está en millones de pesos.

Fuente: Elaboración propia con datos de Banco de México, Indicadores del Sector Externo e Informe Anual, varios números.

Cuadro 2. Tasas de crecimiento y participaciones relativas.

\begin{tabular}{|c|c|c|c|c|c|c|}
\hline Año & $\begin{array}{c}\text { Var.\% expor. } \\
\text { Manufacturas } \\
\text { sin maquila }\end{array}$ & $\begin{array}{c}\text { Tasa de crecimiento } \\
\text { de la industria } \\
\text { manufacturera }\end{array}$ & $\begin{array}{c}\text { Exp. Manufact. } \\
\text { Sin maquila/PIB } \\
\text { manufact. }\end{array}$ & $\begin{array}{c}\text { Var.\% exp. } \\
\text { Manufacturas }\end{array}$ & $\begin{array}{c}\text { Export. } \\
\text { Man/exp } \\
\text { Totales }\end{array}$ & $\begin{array}{c}21.00 \% \\
(X+M) / P I B\end{array}$ \\
\hline 1983 & & & 3.34 & & $24.00 \%$ & $28.29 \%$ \\
\hline 1984 & 28.21 & 5.08 & 4.07 & -7.97 & $24.00 \%$ & $29.54 \%$ \\
\hline 1985 & -7.97 & 6.07 & 3.54 & 23.04 & $36.30 \%$ & $31.08 \%$ \\
\hline 1986 & 23.04 & -5.33 & 4.59 & 31.84 & $37.80 \%$ & $33.75 \%$ \\
\hline 1987 & 31.84 & 3.12 & 5.87 & 17.66 & $40.00 \%$ & $32.32 \%$ \\
\hline 1988 & 17.66 & 0.52 & 6.88 & 6.71 & $37.22 \%$ & $34.21 \%$ \\
\hline 1989 & 6.71 & 7.89 & 6.80 & 13.52 & $36.50 \%$ & $27.67 \%$ \\
\hline 1990 & 13.52 & 6.77 & 7.23 & 117.39 & $75.68 \%$ & $32.30 \%$ \\
\hline 1991 & 5.50 & 3.43 & 7.38 & 11.95 & $78.30 \%$ & $29.79 \%$ \\
\hline 1992 & 6.77 & 4.16 & 7.56 & 17.83 & $82.10 \%$ & $29.08 \%$ \\
\hline 1993 & 18.47 & -0.67 & 9.02 & 18.27 & $82.80 \%$ & $33.33 \%$ \\
\hline 1994 & 21.69 & 4.07 & 10.54 & 32.05 & $83.70 \%$ & $53.11 \%$ \\
\hline 1995 & 46.91 & -4.94 & 16.29 & 20.65 & $83.70 \%$ & $55.81 \%$ \\
\hline 1996 & 22.37 & 10.83 & 17.99 & 18.05 & $85.80 \%$ & $54.94 \%$ \\
\hline 1997 & 14.41 & 9.94 & 18.72 & 11.88 & $90.30 \%$ & $57.68 \%$ \\
\hline 1998 & 6.73 & 7.37 & 18.61 & 15.11 & $89.50 \%$ & $58.06 \%$ \\
\hline 1999 & 9.91 & 4.21 & 19.63 & 19.04 & $87.30 \%$ & $59.34 \%$ \\
\hline 2000 & 13.11 & 6.90 & 20.77 & -2.74 & $89.20 \%$ & $52.90 \%$ \\
\hline 2001 & -2.12 & -3.71 & 21.12 & 0.46 & $88.37 \%$ & $51.68 \%$ \\
\hline 2002 & -0.81 & -0.63 & 21.08 & & & \\
\hline
\end{tabular}

A partir de 1991 se incluye la industria maquiladora en las exportaciones de manufacturas.

Fuente: Elaboración propia con base en el cuadro 1. 
Estrategias de comercio e integración de México

Carlos Gómez Chiñas

Cuadro 3. México: Balanza Comercial Regional

\begin{tabular}{|c|c|c|c|c|c|c|}
\hline Años & $\begin{array}{c}\text { Total } \\
\text { Exportaciones }\end{array}$ & Importac. & $\begin{array}{c}\text { EEUU } \\
\text { Exportaciones }\end{array}$ & Importaciones & $\begin{array}{c}\text { Canadá } \\
\text { Exportaciones }\end{array}$ & Importaciones \\
\hline 1993 & 51886 & 65367 & 43068 & 46467 & 1541 & 1163 \\
\hline 1994 & 60882 & 79346 & 51680 & 54762 & 1497 & 1621 \\
\hline 1995 & 79824 & 72476 & 66618 & 53829 & 1979 & 1374 \\
\hline 1996 & 96000 & 89469 & 80574 & 67536 & 2172 & 1744 \\
\hline 1997 & 110431 & 109808 & 94302 & 82001 & 2157 & 1968 \\
\hline 1998 & 117460 & 125373 & 103093 & 93258 & 1519 & 2290 \\
\hline 1999 & 136391 & 141975 & 120393 & 105267 & 2391 & 2949 \\
\hline 2000 & 166455 & 174458 & 147686 & 127534 & 3353 & 4017 \\
\hline 2001 & 158433 & 168396 & 140296 & 113767 & 3070 & 4235 \\
\hline 2002 & 160682 & 168679 & 142954 & 106557 & 2809 & 4480 \\
\hline Años & $\begin{array}{l}\text { Unión Europ. } \\
\text { Exportac. }\end{array}$ & Importac. & $\begin{array}{c}\text { China } \\
\text { Exportac. }\end{array}$ & Importaciones & $\begin{array}{c}\text { Japón } \\
\text { Exportac. }\end{array}$ & Importaciones \\
\hline 1993 & & & & & 700 & 3369 \\
\hline 1994 & 2985 & 9576 & 42 & 500 & 1001 & 4780 \\
\hline 1995 & 4020 & 7140 & 37 & 521 & 928 & 3608 \\
\hline 1996 & 3507 & 7732 & 38 & 760 & 1393 & 4132 \\
\hline 1997 & 3985 & 9901 & 46 & 1247 & 1156 & 4334 \\
\hline 1998 & 3883 & 11683 & 106 & 1617 & 851 & 4537 \\
\hline 1999 & 5203 & 12951 & 126 & 1921 & 776 & 5083 \\
\hline 2000 & 5610 & 15033 & 204 & 2880 & 931 & 6466 \\
\hline 2001 & 5334 & 16314 & 282 & 4027 & 621 & 8086 \\
\hline 2002 & 5219 & 16628 & 456 & 6274 & 469 & 9349 \\
\hline
\end{tabular}

Fuente: Elaboración propia con datos del Banco de México, Informe Anual, varios años.

Gráfica 1 Índice del tipo de cambio real y exportaciones

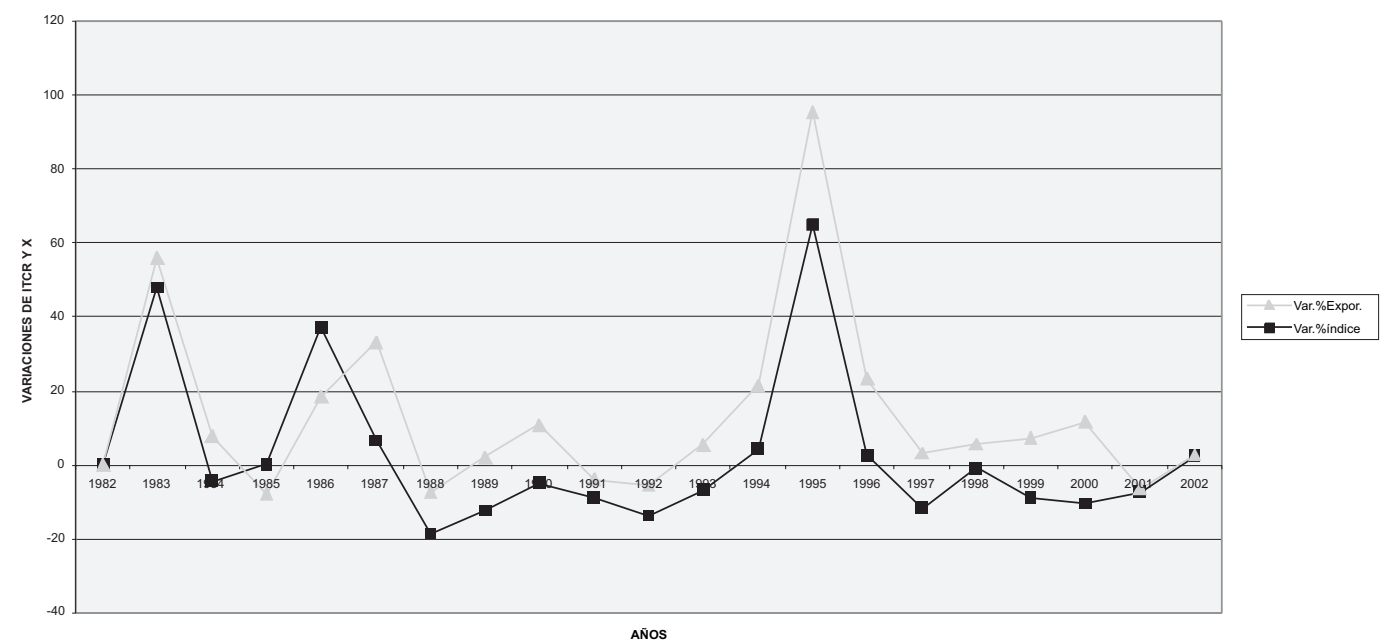

Fuente: Elaboración propia con base en datos del Banco de México, Informe Anual, varios años. 